\title{
Evaluation of the transmitted exposure through lead equivalent aprons used in a radiology department, including the contribution from backscatter
}

\author{
Emmanuel G. Christodoulou, Mitchell M. Goodsitt, Sandra C. Larson, Katie L. Darner, \\ Jahangir Satti, a) and Heang-Ping Chan \\ Department of Radiology, University of Michigan, Ann Arbor, Michigan 48109-0030
}

(Received 16 October 2002; accepted for publication 18 March 2003; published 23 May 2003)

\begin{abstract}
A study was conducted to evaluate the radiation transmission through lead equivalent aprons that are used in a radiology department. A large area beam (poor geometry) was employed for the transmission measurements, and backscatter was simulated by placing 7" of Lucite behind each apron. Separate ionization chambers were used to measure the incident and transmitted $\mathrm{x}$-ray beams. Transmission measurements were made at $70 \mathrm{kVp}$ and $100 \mathrm{kVp}$ through aprons and protective shields from eight different vendors that were marked $0.25 \mathrm{~mm}$ and $0.5 \mathrm{~mm}$ lead equivalent. Transmissions through $0.254 \mathrm{~mm}$ and $0.508 \mathrm{~mm}$ of pure lead were also measured and were compared with the transmissions through the lead equivalent materials. In addition, the area densities of the aprons were measured to compare radiation transmission with respect to the weights of the aprons. At $70 \mathrm{kVp}$, the transmission through $0.254 \mathrm{~mm}$ of pure lead was $5.4 \%$ and the transmissions through the $0.25 \mathrm{~mm}$ lead equivalent materials were $4.3 \%$ to $10.2 \%$ with a mean value of $7.1 \%$ and a standard deviation (s.d.) of $1.4 \%$. At $100 \mathrm{kVp}$, the values were $15 \%$ for $0.254 \mathrm{~mm}$ pure lead and $12.3 \%$ to $20.7 \%$ (mean $16.8 \%$, s.d. $2.1 \%$ ) for the $0.25 \mathrm{~mm}$ lead equivalent materials. The transmission through the $0.508 \mathrm{~mm}$ pure lead sample was $0.9 \%$ at $70 \mathrm{kVp}$, and the corresponding transmissions through the $0.5 \mathrm{~mm}$ lead equivalent materials were $0.6 \%$ to $1.6 \%$ (mean $1.0 \%$, s.d. $0.2 \%$ ). At $100 \mathrm{kVp}$, the transmission through the $0.508 \mathrm{~mm}$ lead sample was $5 \%$ and those through the 0.5 $\mathrm{mm}$ lead equivalent materials were $3.5 \%$ to $6.7 \%$ (mean $4.9 \%$, s.d. $0.7 \%$ ). The radiation transmissions at $70 \mathrm{kVp}$, through two "lead-free" $0.5 \mathrm{~mm}$ lead equivalent aprons, were $1.7 \%$ and $1.9 \%$ and at $100 \mathrm{kVp}$ the transmissions were $6.1 \%$ and $6.8 \%$, respectively. This study indicates that there is a need to establish methods for acceptance testing of aprons and a need to establish acceptance limits for the $\mathrm{x}$-ray transmission of aprons at specific $\mathrm{kVp}$ values. There is also a need for the establishment of appropriate methods and frequencies of routine quality assurance testing of radiation protection aprons. (C) 2003 American Association of Physicists in Medicine.
\end{abstract}

[DOI: $10.1118 / 1.1573207]$

Key words: apron, fluoroscopy, protection, radiation, transmission

\section{INTRODUCTION}

Lead equivalent aprons are the primary means of radiation protection for personnel working in an x-ray environment. One concern is the heavy weight of these aprons. Two epidemiologic studies have been performed to assess the relationship between back pain and the use of lead aprons. In one of these studies, Moore et al. ${ }^{1}$ found that there was not a significant difference between the number of reports of back pain for radiologists who wore lead aprons less than ten hours per week compared to those who wore aprons for more than 10 hours per week. In another study, Ross et al. ${ }^{2}$ found that cardiologists who wore lead aprons for much longer periods of time than the radiologists in Moore's study (e.g., 8.4 hours per day) had "substantially greater frequency of skeletal complaints, and more missed days from work due to pain" when compared with control groups of orthopedic surgeons and rheumatologists. Ross et al. concluded in their study that "interventionalist's disc disease" due to wearing lead aprons for extended periods of time is a distinct occupational hazard of interventional cardiologists. The conclu- sions of Ross et al. should also apply to interventional radiologists who likewise often wear aprons for 8 or more hours per day.

Several researchers have proposed methods to reduce the back pain problem. Stevens ${ }^{3}$ suggested affixing a Velcro band to the front of the apron and wrapping that band snuggly about the waist just above the iliac crest. This results in most of the weight of the apron being supported by the pelvis resulting in less stress on the back and less back pain. Boothroyd and Russell ${ }^{4}$ proposed a modified apron design with wider shoulders and a higher neckline to shield more of the wearer's bone marrow. They performed calculations to show that a $0.25 \mathrm{~mm}$ lead equivalent apron with their new design would result in less dose (skin dose $x \%$ unprotected marrow + attenuated skin dose $x \%$ of covered marrow) to the wearer than even a $3.0 \mathrm{~mm}$ lead equivalent apron of conventional design. However, they neglected to account for the use of a thyroid shield with conventional aprons.

Another means to reduce the weight of aprons is to use composite materials. Webster was the first to propose the use of composites consisting of lead, tin, iodine, and barium and 
experimentally determined that such composites could achieve the equivalent attenuation of pure lead for $\mathrm{x}$ rays generated at 50 to $125 \mathrm{kVp}$ with a $20 \%$ to $30 \%$ weight reduction. ${ }^{5}$ This work resulted in the production and wide use of aprons made of multiple layers of polyvinyl chloride loaded with antimony and lead. ${ }^{5,6}$ Antimony $(Z=51)$ was employed instead of tin $(Z=50)$ in these aprons because of its lower cost per pound. ${ }^{6}$ About 25 years later, Yaffe et al. developed aprons made of similar materials including barium, tungsten, and lead. ${ }^{7}$ They analytically determined the optimal compositions in terms of attenuation and weight of such aprons at $70 \mathrm{kVp}, 100 \mathrm{kVp}$, and $120 \mathrm{kVp}$. They found that an apron containing $1.65 \mathrm{~kg} / \mathrm{m}^{2}$ lead, $1.65 \mathrm{~kg} / \mathrm{m}^{2}$ tungsten, and $1.20 \mathrm{~kg} / \mathrm{m}^{2}$ barium yielded almost the same attenuation (slightly more at $70 \mathrm{kVp}$, but less at $100 \mathrm{kVp}$ and $120 \mathrm{kVp})$ as that of $0.5 \mathrm{~mm}$ pure lead $\left(5.65 \mathrm{~kg} / \mathrm{m}^{2}\right)$ with a 25-30\% weight reduction. Hubbert et al. compared the x-ray attenuation of xenolite, a composite of lead, antimony, and tungsten $\left(5.56 \mathrm{~kg} / \mathrm{m}^{2}\right)$ with a $0.5 \mathrm{~mm}$ lead/vinyl apron $\left(7.92 \mathrm{~kg} / \mathrm{m}^{2}\right)$ using radiation scattered from patients, phantoms, and the primary beam, ${ }^{8}$ and reported that the $0.5 \mathrm{~mm}$ lead apron "produced the highest measured attenuation... for all exposures, but statistically, the composite had a similar degree of radiation absorption at a weight that was $29.8 \%$ lighter." Murphy et al. measured the attenuation properties of two commercially available composite (lead, tin, yttrium, and copper) aprons at various energies. ${ }^{9}$ They concluded that "for low-energy diagnostic x rays," such aprons "offer a substantial advantage in weight reduction, with transmission increased by only a slight percentage."

In sales brochures, aprons such as those discussed above are commonly referred to as "lead equivalent" and we use this term in this paper. It should be noted that such aprons are actually lead equivalent in their x-ray attenuation only within a specific energy range and their attenuation may be different than lead at other energies. The compositions of lead equivalent aprons are in most cases not readily available, and it is possible that some are better than others in attenuating $\mathrm{x}$ rays. We performed a study to evaluate a variety of these aprons. We measured the transmission through aprons with nominal lead equivalent thicknesses of 0.25 and $0.5 \mathrm{~mm}$ at $70 \mathrm{kVp}$ and $100 \mathrm{kVp}$. Furthermore, we determined the weight per unit area of the aprons and correlated these area densities with the $\mathrm{x}$-ray transmissions.

\section{MATERIALS AND METHODS}

Over 40 aprons from our Radiology Department were studied. These aprons included models from (1) BurkhartRoentgen International Inc, St. Petersburg, FL, (2) INFAB Corporation, Camarillo, CA, (3) Peak International, Scottsboro, AL, (4) AADCO Medical, Inc., Randolph, VT, (5) Bar Ray Products, Littlestown, PA, (6) BT Medical Company, Bridgeport, PA, (7) LiteTech, Bridgeport, PA, and (8) Picker Health Care Products, Cleveland, OH. The x-ray transmission measurements were performed using a Philips Optimus radiographic unit (high frequency generator) (Philips Medical Systems N.A., Bothell, WA.). The half-value layer at 80
$\mathrm{kVp}$ for this unit was $3.3 \mathrm{~mm}$ of aluminum. A 7 inch thick Lucite phantom was employed to simulate the backscatter from a person wearing a lead apron. This phantom was placed on the tabletop, which was at a distance of $100 \mathrm{~cm}$ from the focal spot. The main ionization chamber, a Radcal (Radcal Corporation, Monrovia, CA) 6 cc (model 10X5-6) interfaced with a 9010RM-S dosimeter, was placed on top of the 7 inch thick Lucite phantom so that all measured exposures included backscatter from the phantom. A Keithley (Keithley Instruments, Cleveland, Ohio) 15-cc (model 96035) reference ionization chamber interfaced with a 35050A dosimeter was placed in the beam near the focal spot. The exposures measured with this monitoring chamber were used for normalization of the $\mathrm{x}$-ray output. The $\mathrm{x}$-ray field size at the apron was $31 \mathrm{~cm} \times 39 \mathrm{~cm}$, and was totally intercepted by the Lucite phantom. Thus, the measurements were made using "poor" geometry. This simulated the condition in which scatter from a large irradiated region in a patient undergoing a fluoroscopy/angiography procedure strikes a radiologist's lead apron. Although our measurement geometry did not fully simulate the hardened spectrum of the scattered $\mathrm{x}$ rays originating from the patient, it had two advantages. It permitted measurements under well-defined conditions (1) without excessive x-ray tube loading and (2) without use of much larger or more sensitive ionization chambers that might have been required had the incident $\mathrm{x}$-ray beam been generated by scatter from a patient-simulating phantom.

$\mathrm{X}$-ray transmission was measured for lead equivalent aprons with nominal thicknesses of $0.25 \mathrm{~mm}$, and $0.5 \mathrm{~mm}$. To measure lead apron transmission, each apron was placed on top of the 6-cc ionization chamber, which lay on top of the Lucite phantom. For the aprons that had $0.5 \mathrm{~mm}$ lead equivalent material on the front and sides, and $0.25 \mathrm{~mm}$ lead equivalent material on the back, each section was measured separately. The transmission $(T)$ through each individual apron was computed as

$$
T=\left(Y_{1} / y\right) /\left(X_{1} / x\right),
$$

where $Y_{1}$ is the exposure that was measured through the apron with the 6-cc chamber and $y$ is the corresponding exposure measured with the 15 -cc reference chamber, $X_{1}$ is the exposure reading obtained with the 6-cc chamber when no apron was present and $x$ is the corresponding reading obtained with the 15-cc reference chamber. All of the measurements were made with the $\mathrm{x}$-ray unit set at the selected $\mathrm{kVp}$ (either $70 \mathrm{kVp}$ or $100 \mathrm{kVp}$ in our case).

Transmission was also measured through 0.254 and 0.508 $\mathrm{mm}$ thick pure lead at $70 \mathrm{kVp}$ and $100 \mathrm{kVp}$ under the same experimental conditions.

In addition, we weighed many of the aprons on a calibrated scale and measured the areas with a tape measure in order to compute the weight per unit area. For those aprons that did not have a uniform thickness (i.e., $0.25 \mathrm{~mm}$ thickness on the sides/back and $0.5 \mathrm{~mm}$ in front, as indicated by the manufacturer on the apron tag), the weight for each individual apron panel was estimated based on the total apron weight and the assumption of uniform material density. For example, to estimate the weights of the individual panels of 
TABLE I. Transmission range, mean and standard deviation values for 0.25 $\mathrm{mm}$ and $0.5 \mathrm{~mm}$ lead equivalent aprons at $70 \mathrm{kVp}$ and at $100 \mathrm{kVp}$.

\begin{tabular}{ccccccc}
\hline \hline $\mathrm{kVp}$ & $\begin{array}{c}\text { Thickness } \\
(\mathrm{mm})\end{array}$ & $\begin{array}{c}\text { Number } \\
\text { of } \\
\text { aprons }\end{array}$ & $\begin{array}{c}\text { Transmission } \\
\text { range }(\%)\end{array}$ & Mean & SD & $\begin{array}{c}\text { Transmission } \\
\text { through } \\
\text { pure lead }(\%)\end{array}$ \\
\hline 70 & 0.25 & 24 & $4.3-10.2$ & 7.05 & 1.4 & 5.4 \\
& 0.5 & 34 & $0.6-1.6$ & 1.03 & 0.2 & 0.9 \\
100 & 0.25 & 24 & $12.3-20.7$ & 16.8 & 2.1 & 15.0 \\
& 0.5 & 34 & $3.5-6.7$ & 4.9 & 0.7 & 5.0 \\
\hline \hline
\end{tabular}

an apron with one $0.5 \mathrm{~mm}$ panel of area $A_{1}$ and one $0.25 \mathrm{~mm}$ panel of area $A_{2}$, and a total weight $W_{T}$, we solved the set of equations

$$
\begin{aligned}
& \frac{W_{1}}{A_{1}^{*} 0.5 \mathrm{~mm}}=\frac{W_{2}}{A_{2}{ }^{*} 0.25 \mathrm{~mm}}, \\
& W_{T}=W_{1}+W_{2}
\end{aligned}
$$

for the weights $W_{1}$ and $W_{2}$.

We tried to correlate the transmissions through the aprons with their weight per unit area. The variation in transmission for aprons from the same manufacturer with the same nominal lead equivalent thicknesses was also computed. To evaluate the reproducibility of our results, transmission measurements were repeated three times at the same location in three aprons. This was performed at both 70 and $100 \mathrm{kVp}$. In addition, to assess transmission uniformity, radiation transmissions were measured at three different locations on each of these three aprons.

\section{RESULTS AND DISCUSSION}

The transmission ranges, mean values, and standard deviation values for different apron thicknesses and pure lead are summarized in Table I. At $70 \mathrm{kVp}$, the transmission through $0.254 \mathrm{~mm}$ of pure lead was $5.4 \%$ and the transmissions through the $0.25 \mathrm{~mm}$ lead equivalent materials were from $4.3 \%$ to $10.2 \%$ with a mean value of $7.1 \%$ and a standard deviation (s.d.) of $1.4 \%$. At $100 \mathrm{kVp}$, the values were $15 \%$ for $0.254 \mathrm{~mm}$ pure lead and $12.3 \%$ to $20.7 \%$ (mean $16.8 \%$, s.d. $2.1 \%$ ) for the $0.25 \mathrm{~mm}$ lead equivalent materials. The transmission through the $0.508 \mathrm{~mm}$ pure lead sample was $0.9 \%$ at $70 \mathrm{kVp}$, and the corresponding transmissions through the $0.5 \mathrm{~mm}$ lead equivalent materials were $0.6 \%$ to $1.6 \%$ (mean $1.0 \%$, s.d. $0.2 \%$ ). At $100 \mathrm{kVp}$, the transmission through the $0.508 \mathrm{~mm}$ lead sample was $5 \%$ and those through the $0.5 \mathrm{~mm}$ lead equivalent materials were $3.5 \%$ to $6.7 \%$ (mean $4.9 \%$, s.d. $0.7 \%$ ). Radiation transmission results for the nominal $0.25 \mathrm{~mm}$ and $0.5 \mathrm{~mm}$ lead equivalent aprons at $70 \mathrm{kVp}$ are shown in Fig. 1. Figure 2 shows the transmission results for the same aprons at $100 \mathrm{kVp}$. Both figures also include the transmission of two $0.5 \mathrm{~mm}$ lead equivalent lead free aprons and the pure lead samples. Plots of the transmissions at $70 \mathrm{kVp}$ for $0.25 \mathrm{~mm}$ and $0.5 \mathrm{~mm}$ lead equivalent aprons as a function of the measured weight per unit area of the aprons are shown in Fig. 3, and those for $100 \mathrm{kVp}$ are shown in Fig. 4. As can be seen in these figures, although the
$70 \mathrm{kVp}, 0.25 \mathrm{~mm}$ lead equivalent

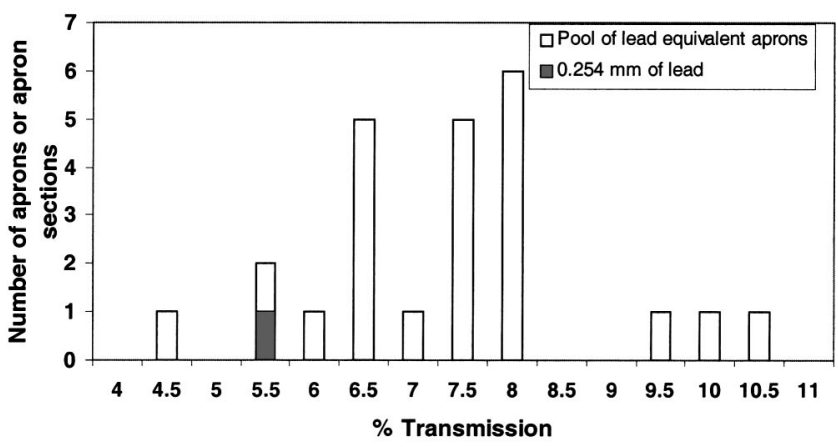

$70 \mathrm{kVp}, 0.5 \mathrm{~mm}$ lead equivalent

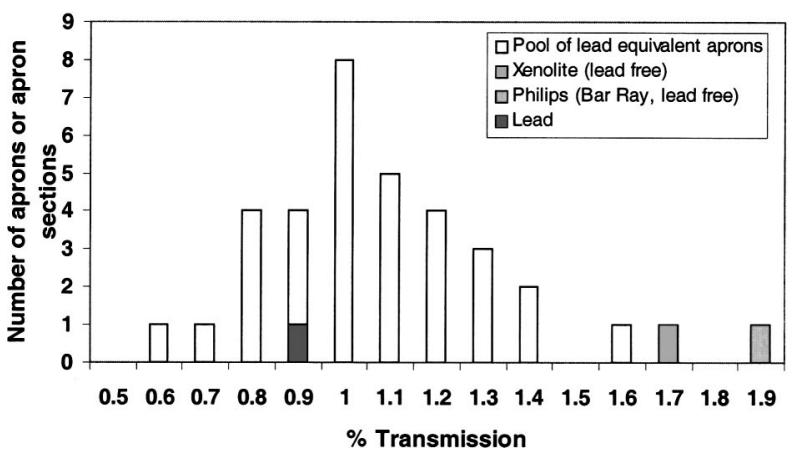

FIG. 1. Transmission (\%) histograms for lead equivalent aprons of nominal $0.25 \mathrm{~mm}$ and $0.5 \mathrm{~mm}$ thicknesses at $70 \mathrm{kVp}$.

trend indicates that aprons with higher weight per unit area demonstrate higher $\mathrm{x}$-ray attenuation, the correlation coefficients for linear fits to the data are much lower than anticipated. Similar results are obtained for exponential fits to the data. (For $0.25 \mathrm{~mm}$ and $0.5 \mathrm{~mm}$ of lead equivalent thickness at $70 \mathrm{kVp}$ the square of the correlation coefficient, $R^{2}$, has values of 0.26 and 0.52 , respectively, and at $100 \mathrm{kVp} R^{2}$ has values of 0.29 and 0.56 , respectively.) This may partially be explained by the fact that the error in the estimation of the area of an apron is significant. This estimation can be made much more accurate if samples with simple geometrical shapes, instead of actual aprons, are used. Other reasons could be the variations in the weights of the binder and cover materials that are employed in the aprons as well as the differences in the weights of the materials employed for lead equivalence. $^{7}$

The reproducibility of the transmission measurements through three aprons as represented by the coefficient of variation (standard deviation/mean) was within $0.4 \%$ at 70 $\mathrm{kVp}$ and within $0.01 \%$ at $100 \mathrm{kVp}$. The uniformity of the measurements at three locations on these aprons was within $3 \%$ at $70 \mathrm{kVp}$, and within $2 \%$ at $100 \mathrm{kVp}$.

The variation in transmission, at certain $\mathrm{kVps}$ and equivalent thicknesses, for aprons from the individual manufacturer were also compared (i.e., the transmission range for $0.5 \mathrm{~mm}$ lead equivalent aprons from manufacturer A was compared with the transmission range for $0.5 \mathrm{~mm}$ lead equivalent aprons from manufacturer B). Each manufacturer may or 
$100 \mathrm{kVp}, 0.25 \mathrm{~mm}$ lead equivalent

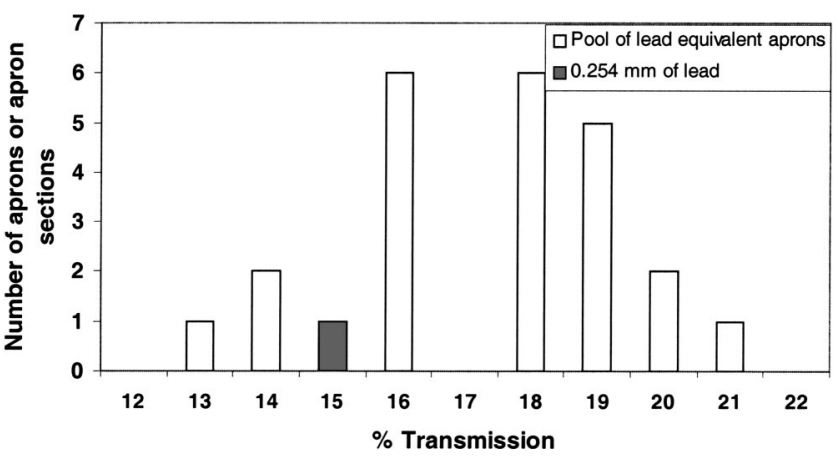

$100 \mathrm{kVp}, 0.5 \mathrm{~mm}$ lead equivalent

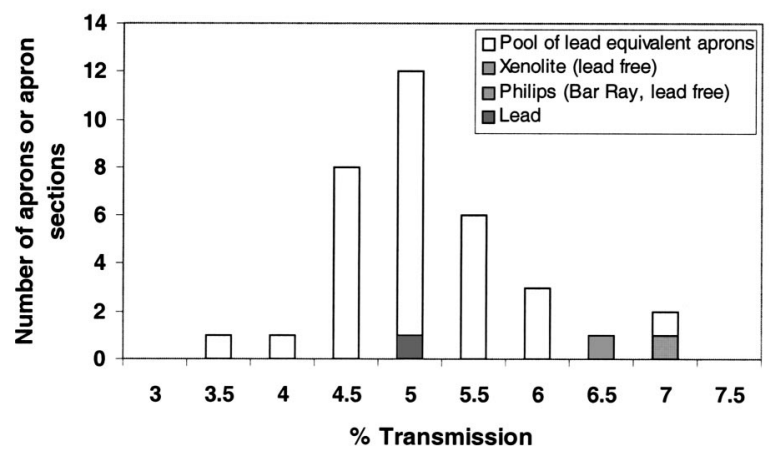

FIG. 2. Transmission (\%) histograms for lead equivalent aprons of nominal $0.25 \mathrm{~mm}$ and $0.5 \mathrm{~mm}$ thicknesses at $100 \mathrm{kVp}$.

may not have been represented by different apron models.

We found that the largest transmission range for aprons from the same manufacturer with the same nominal lead equivalent thickness of $0.25 \mathrm{~mm}$ was from $9.1 \%$ to $10.2 \%$ at $70 \mathrm{kVp}$ with the same weight per unit area of $3.1 \mathrm{~kg} / \mathrm{m}^{2}$. At $100 \mathrm{kVp}$ the largest transmission range for $0.25 \mathrm{~mm}$ lead equivalent aprons was for a different manufacturer than at 70 $\mathrm{kVp}$. The range was found to be from $17.0 \%$ to $18.7 \%$, with weights per unit area in the range of 2.8 to $3.6 \mathrm{~kg} / \mathrm{m}^{2}$.

In contrast, $0.5 \mathrm{~mm}$ lead equivalent aprons from the same manufacturers showed far greater variability in their transmissions. The largest transmission range for $0.5 \mathrm{~mm}$ lead equivalent aprons from the same manufacturer was from $0.9 \%$ to $1.6 \%$ at $70 \mathrm{kVp}$, and from $4.4 \%$ to $6.7 \%$ at $100 \mathrm{kVp}$ with weights per unit area in the range from 6.1 to $8 \mathrm{~kg} / \mathrm{m}^{2}$.

The average transmission of the pool of the leadcontaining $0.5 \mathrm{~mm}$ lead equivalent aprons is $1.03 \%(0.89 \%$ median) at $70 \mathrm{kVp}$, and $4.93 \%$ (4.86\% median) at $100 \mathrm{kVp}$. The average weight per unit area of these aprons is 7.06 $\mathrm{kg} / \mathrm{m}^{2}$. In contrast, the transmissions through the two leadfree $0.5 \mathrm{~mm}$ lead equivalent aprons were measured to be $1.7 \%$ and $1.9 \%$ at $70 \mathrm{kVp}$, and $6.1 \%$ and $6.8 \%$, respectively, at $100 \mathrm{kVp}$. The weights per unit area of these aprons were $5.7 \mathrm{~kg} / \mathrm{m}^{2}$ and $5.3 \mathrm{~kg} / \mathrm{m}^{2}$, respectively. Therefore, under the experimental conditions described above, for an average weight reduction of $28 \%$ the lead free aprons allow on the average a $73 \%$ increase in transmission at $70 \mathrm{kVp}$ and a $31 \%$
$70 \mathrm{kVp}, 0.25 \mathrm{~mm}$ lead equivalent

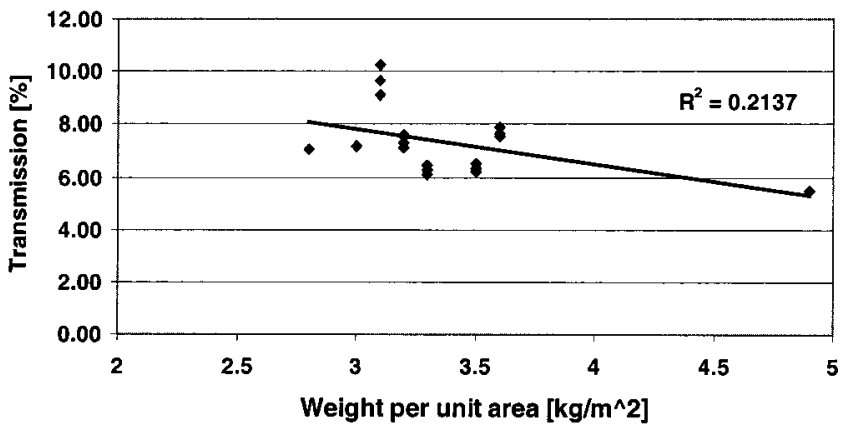

$70 \mathrm{kVp}, 0.5 \mathrm{~mm}$ lead equivalent

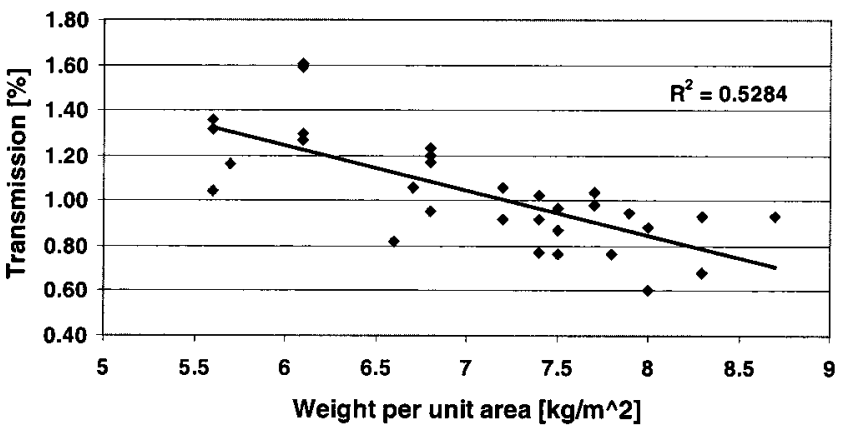

FIG. 3. Variations in percentage radiation transmission through $0.25 \mathrm{~mm}$ and $0.5 \mathrm{~mm}$ lead equivalent aprons at $70 \mathrm{kVp}$ as a function of weight per unit area.

increase in transmission at $100 \mathrm{kVp}$ when compared with the lead-containing $0.5 \mathrm{~mm}$ lead equivalent aprons.

\section{CONCLUSION}

This study shows that there are significant differences in the transmissions of aprons of similar nominal lead equivalent thicknesses. These differences are most pronounced for the $0.25 \mathrm{~mm}$ lead equivalent aprons from various manufacturers. For these aprons, the transmissions ranged from $4.3 \%$ to $10.2 \%$ at $70 \mathrm{kVp}$, which is a difference of more than a factor of 2. At $100 \mathrm{kVp}$, the transmissions ranged from $12.3 \%$ to $20.7 \%$, or a factor of 1.7 . There is also a significant variation in the radiation transmission of lead aprons of 0.5 $\mathrm{mm}$ nominal lead equivalent thicknesses manufactured by the same company. ${ }^{7}$ Unfortunately, the compositions of the protective aprons are not made public. Therefore, it was not possible for us to correlate the transmissions of the aprons with their compositions.

For an average weight reduction of $28 \%$, two lead free 0.5 $\mathrm{mm}$ lead equivalent aprons allow on the average a $73 \%$ increase in transmission at $70 \mathrm{kVp}$ and a $31 \%$ increase in transmission at $100 \mathrm{kVp}$ when compared with the lead containing $0.5 \mathrm{~mm}$ lead equivalent aprons.

No clear relationship between weight and radiation protection (Figs. 3 and 4) could be established in this study. To our knowledge, there are no State or Federal regulations or standards for acceptance testing of lead or lead equivalent aprons at present. Also, there are no guidelines for lead 
$100 \mathrm{kVp}, 0.25 \mathrm{~mm}$ lead equivalent

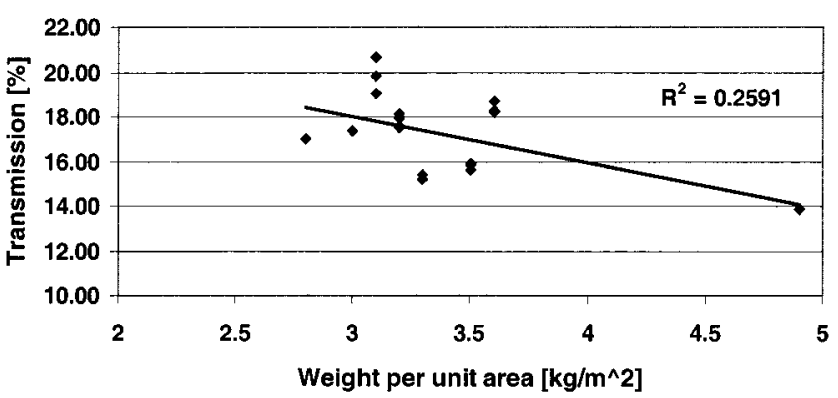

$100 \mathrm{kVp}, 0.5 \mathrm{~mm}$ lead equivalent

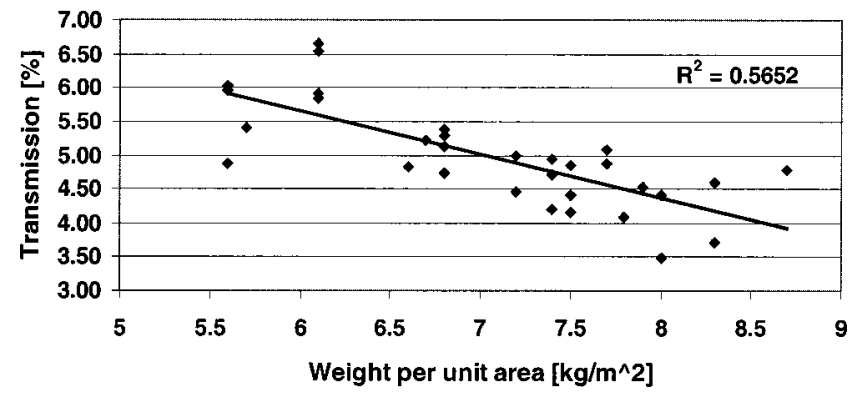

FIG. 4. Variations in percentage radiation transmission through $0.25 \mathrm{~mm}$ and $0.5 \mathrm{~mm}$ lead equivalent aprons at $100 \mathrm{kVp}$ as a function of weight per unit area.

equivalent transmission limits. Standardized methods for acceptance testing of lead aprons are needed. In particular, methods for measuring the $\mathrm{x}$-ray transmission of aprons, and acceptance limits for the transmission of aprons of nominal lead equivalence at specific $\mathrm{kVp}$ values should be defined. An international standard (IEC $61331^{10}$ ) has been published that could be used as a resource for establishing testing methods and acceptance limits. Part 1 of this standard "specifies the methods of determining and indicating the attenuation properties of materials" in sheet form that are used as protective devices against diagnostic medical x rays. Part 3 of the standard deals, among other things, with standard sizes, particular design features and minimum attenuation properties of materials. To our knowledge, this international standard has not yet been widely accepted or utilized.

Routine QC tests for the evaluation of aprons should be established. Some of the issues that need to be addressed include the type of the tests (transmission measurement, visual inspection, and fluoroscopic inspection for holes and cracks), the frequencies of the tests, and the acceptance limits (e.g., how big a hole is acceptable ${ }^{11}$ and what transmission is acceptable). We believe an AAPM task group should be established to address these issues. In the interim, we recommend the following: Qualified personnel under the direction of a medical physicist should perform acceptance tests on all new aprons. The acceptance test should include (1) visual inspection for tears and other physical imperfections, (2) fluoroscopic imaging of the aprons to detect holes, cuts, and thickness variations, and (3) radiographic transmission measurements using a technique similar to the one employed in this paper, using poor geometry and Lucite backscatter. In accordance with the policy recommended by Glaze, LeBlanc, and Bushong, ${ }^{11}$ aprons should be rejected or sent back for patching if they have cracks in excess of $1 \mathrm{~cm}$ and holes that are larger than $2 \mathrm{~mm}$ (as established on a contact radiograph). If the aprons are found to be nonuniform by fluoroscopy, the thinnest and average thickness regions should be identified from the fluoroscopic image and the $\mathrm{x}$-ray transmissions should be measured in those regions. Based on our measurement geometry and x-ray beam quality, as can be seen in Figs. 1 and 2, the distribution of the x-ray transmission of lead equivalent aprons is fairly wide. While the average transmission for lead equivalent aprons of a given nominal thickness and the transmission through the same thickness of pure lead are very close to each other, there are a number of aprons with significantly higher transmission than pure lead. In addition, the transmissions of the lead free aprons are located at the higher end of the distribution. The exact transmission thresholds for rejecting aprons are yet to be determined. It is our experience that we can probably say that aprons of the exact same type (manufacturer, model and indicated thickness) are "very reproducible" if they are made from the same "batch" of material (i.e., 10 aprons ordered at the same time would probably be from the same "batch" of material and would be "very reproducible"). We cannot generalize this statement for aprons that were made from a different "batch." This is due to the variability that may exist in the source of the raw material and/or the manufacturing process. The manufacturers should be required to standardize their methods of transmission measurement and devise methods to minimize batch-to-batch variability. In addition to labeling their aprons with a lead equivalence at specific $\mathrm{kVp}(\mathrm{s})$, manufacturers should also be required to present transmission curves at a range of $\mathrm{kVp}$ values in their product literature. Enforcement of the lead equivalent requirement or specification might fall under the auspices of the FDA or some other federal government agency. Following the acceptance tests, medical physicists should supervise the performance of routine QC tests of the aprons annually. Our recommendation is that the aprons should be fluoroscopically examined every year. In addition, the wearer of the apron should visually examine the apron for tears, holes, and other imperfections daily or weekly and request a fluoroscopic examination of the apron if a defect is suspected. Establishing acceptance criteria and routine tests such as those recommended above should lead to improved safety for all radiation personnel.

\footnotetext{
${ }^{a)}$ Present address: Department of Radiation Physics, St. Joseph's Medical Center, 1800 N. California St., Stockton, CA 95204.

${ }^{1}$ B. Moore, E. VanSonnenberg, G. Casola, and R. Novelline, "The relationship between back pain and lead apron use in radiologists," AJR, Am. J. Roentgenol. 158, 191-193 (1992).

${ }^{2}$ A. M. Ross, J. Segal, D. Borenstein, E. Jenkins, and S. Cho, "Prevalence of spinal disk disease among interventional cardiologists," Am. J. Cardiol. 79, 68-70 (1997).

${ }^{3}$ J. S. Stevens, "Lead apron modification," AJR, Am. J. Roentgenol. 130, 801 (1978)
} 
${ }^{4}$ A. E. Boothroyd and J. G. B. Russell, "The lead apron: room for improvement?,” Br. J. Radiol. 60, 203-204 (1987).

${ }^{5}$ E. W. Webster, "Experiments with medium Z-materials for shielding against low-energy x-rays," Radiology 86, 146 (1966).

${ }^{6} \mathrm{E}$. W. Webster, "Addendum to Composite materials for x-ray protection," Health Phys. 61, 918 (1991).

${ }^{7}$ M. J. Yaffe, G. E. Mawdsley, L. Martin, R. Servant, and R. George, "Composite materials for x-ray protection," Health Phys. 60, 661-664 (1991).

${ }^{8}$ T. E. Hubbert, J. J. Vucich, and M. R. Armstrong, "Lightweight aprons for protection against scattered radiation during fluoroscopy," AJR, Am. J. Roentgenol. 161, 1079-1081 (1993).

${ }^{9}$ P. H. Murphy, Y. Wu, and S. A. Glaze, "Attenuation properties of lead composite aprons," Radiology 186, 269-272 (1993).

${ }^{10}$ International Standard IEC 61331. Protective devices against diagnostic medical X-radiation. Part 1: Determination of attenuation properties of materials. First edition 1994-10. Part 3: Protective clothing and protective devices for gonads. First edition 1998-11.

${ }^{11}$ S. Glaze, A. D. LeBlanc, and S. C. Bushong, "Defects in new protective aprons," Radiology 152, 217-218 (1984). 